\title{
ESTUDIO DE LA CALIDAD MICROBIOLÓGICA DE HELADOS QUE SE EXPENDEN EN LA CIUDAD DE TACNA
}

\author{
STUDY OF MICROBIOLOGICAL QUALITY OF ICE-CREAMS THAT ARE \\ SOLD IN TACNA CITY
}

\author{
${ }^{1}$ Amelia Castro Gamero
}

\begin{abstract}
RESUMEN
En esta investigación se ha determinado cuatro indicadores microbiológicos, la detección de E. coli y la detección de Salmonella en muestras de helado que se expenden en la ciudad de Tacna, además se ha descrito las condiciones de venta de este producto. La toma de muestras se realizó en las principales avenidas de Tacna, los métodos microbiológicos que se utilizaron son los tradicionales, especialmente el de recuento en placa. El grado de contaminación del producto final de los helados depende además de la composición de los ingredientes, de la aplicación correcta de las BPM para helados, de la conservación de la temperatura de almacenamiento y del uso de las buenas prácticas de higiene durante el proceso de venta. Esto se cumple principalmente para los helados que se elaboran artesanal y semi-artesanalmente. Según los resultados, el RTBAMV frente a incorrectas prácticas de higiene puede alcanzar valores elevadisimos de 60 y más millones de ufc/g en los helados. El NMP de coliformes totales (los cuales provienen, del agua de lavado, suelo, manos, vestimenta de trabajadores, utensilios, mesas de trabajo, maquinarias no desinfectadas, dosificadores, etc.) en algunas muestras alcanzó valores $>1100 / \mathrm{g}$ lo cual indica que debe de existir una mayor preocupación por la higiene en la elaboración y venta de helados. No se detectó contaminación fecal a través de E. coli. Algunas muestras presentan elevada numeración de Staphylococcus aureus (del orden de 1100 hasta 1 millón de ufc/g), bacterias termorresistentes causantes de intoxicaciones. Se ha observado elevada numeración de levaduras en casi todas las muestras (desde miles hasta 90 millones de ufc/g), a excepción de la muestra 1. Esto indica la gran dificultad existente para evitar el desarrollo de levaduras en los helados artesanales y semi-artesanales.
\end{abstract}

Palabras Clave: Contaminación, indicadores microbiológicos, intoxicaciones, buenas prácticas de higiene.

\section{ABSTRACT}

In this research four microbiological indicators were found, the detection of E.coli and the detection of Salmonella in ice creams samples that are sold in Tacna city; also the sale conditions of this product are described here. The samples have been taken in the principal avenues of Tacna city; the microbiological methods that were used are the traditional ones, counting in petridishes (plates). The contamination degree of the final ice-cream product depends besides the ingredient composition of the correct application of the good manufacturing practice for ice cream, the conservation of the correct store temperature, and the use of good hygienic practice during the sale process. This is fulfilled principally for the artisanal ice-creams. According to the results, the viable, mesophilic aerobic bacterial count, if there is no good manufacturing practice can be reach elevated values of 60 and more millions ufc/g in ice creams. The more probably number o total coli forms ( they come from washing water, floor, hands, working clothes, working tables, no disinfected machinery and proportioners) in some samples had values $>1100 / \mathrm{g}$ this indicate that there should be more concern for the hygienic elaboration and sale of ice-creams. Rather, there's no detected fecal contamination (E. coli). Other samples had elevate values of enumeration of Staphylococcus aureus (1100 until one million ufc/g), heat-resistant bacteria the cause of intoxications. An elevate enumeration of yeast in almost all samples (thousands until 90 millions ufc/g) has been observed, too. The exception is sample 1 this indicates the difficulty to avoid the reproduction of yeast in artisanal ice-creams.

Key Words: contamination, microbiological indicators, intoxications, good hygienic practice.

\section{INTRODUCCIÓN}

Los helados son productos alimenticios que tienen mucha demanda en los meses de verano pero también en los meses de invierno. Son postres que se venden en la ciudad de Tacna en establecimientos tipo salones de té o en forma ambulatoria, en carritos donde se conservan a temperaturas de congelación.

Los consumidores en su mayoría son niños, adolescentes, mayores y personas de la tercera edad, población que es más propensa a enfermedades infecciosas, intestinales e intoxicaciones.

La mezcla para la elaboración de helados contiene: leche, crema de leche, azúcar, estabilizantes, emulsionantes, 
jarabes a base de frutas o colorantes y esencias, etc. Estos ingredientes son muy susceptibles a contaminaciones por enterobacterias patógenas lactosa positivas y lactosa negativas y además por estafilococos capaces de producir enterotoxinas muy termorresistentes.

Las mezclas para helados deben de someterse a un tratamiento térmico adecuado donde se controlen estrictamente los tiempos y las temperaturas de pasteurización, antes de ser batidas y congeladas. Este control no siempre se realiza correctamente, por lo que con frecuencia los helados pueden ser el vehículo de enfermedades transmitidas por alimentos, ya que los microorganismos patógenos pueden subsistir por mucho tiempo a temperaturas de congelación a pesar de que no se reproduzcan.

En la ciudad de Tacna, se venden helados industrializados, pero una gran mayoría son artesanales o semi-artesanales.

Existen instituciones estatales dedicadas al control higiénico-sanitario de alimentos, como las municipalidades y DIGESA (Dirección General de Salud).

Esta investigación es un aporte actualizado donde se indicará las condiciones de venta de helados y la calidad microbiológica de éstos, en los 09 principales centros de venta más concurridos en la ciudad de Tacna, lo cual permitirá, establecer luego medidas de prevención, corrección en los puntos críticos del proceso de elaboración y en la aplicación de la BPM, en donde sea necesario.

En la ciudad de Tacna, en los últimos años ha aumentado la producción y venta de helados principalmente artesanales. Poseen gran acogida por la población tacneña y turistas provenientes principalmente de la ciudad de Arica.

Las principales causas de contaminación microbiana en los helados son personas portadoras de enfermedades o que posean heridas en las manos, congelación insuficiente del producto, ausencia o deficiencia de tratamiento térmico de la mezcla, materias primas muy contaminadas, el no inmediato enfriamiento o prolongados tiempos de reposo de la mezcla. Todo esto requiere un control en cada lugar de producción y venta. En caso que no se dé un control efectivo, la salud de la población infantil de la ciudad de Tacna se vería principalmente afectada.

Es importante definir las condiciones de venta de los helados en la ciudad de Tacna, por lo cual debe tenerse en cuenta que para obtener productos de excelentes condiciones higiénicas deben seguirse una serie de normas de higiene que comprometan a las empresas productoras de helados. Es necesario luego el control microbiológico de los productos terminados para indicar si se cumplen estas normas.

Asimismo, es importante saber qué grado de contaminación poseen los helados con coliformes totales y fecales, microorganismos aerobios mesófilos, levaduras y hongos, estafilococos patógenos y salmonella. Estos microorganismos son indicadores suficientes para responder si se aplicó las BPM (Buenas prácticas de manufactura) durante la elaboración y venta de helados.

\section{Objetivos:}

Determinar la calidad microbiológica de los helados que se expenden en la ciudad de Tacna utilizando los indicadores microbiológicos adecuados de acuerdo a las normas vigentes en nuestro país.

Definir las condiciones de venta de los helados.

Establecer si se cumplen o no las BPM y normas de higiene en los centros de venta.

\section{MATERIALES Y MÉTODOS}

\subsection{Materiales Equipos:}

Autoclave, Estufa-esterilizadora, Estufaincubadora, baño maría, refrigerador, mechero bunsen, balanza, contador de colonias, cocinillas.

\section{Materiales:}

De vidrio: Placas Petri, tubos de ensayo, campanas Durham, pipetas de 1, 2, 5, $10 \mathrm{ml}$, matraces Erlenmeyer de $50,150,250,500,1000 \mathrm{ml}$, vasos de precipitado de $100 \mathrm{ml}$, probeta de $500 \mathrm{ml}$, probetas de $100 \mathrm{ml}$, balones de 250,500 $\mathrm{ml}$, varillas de vidrio, vasitos porta-muestras.

Otros materiales: Asas de kholle, cucharitas, alcohol, algodón, papel, espátulas.

Medios de Cultivo, y reactivos: Agar plate count, Agar suero naranja, Agar Baird Parker, VRBA, Caldo Brilla, caldo peptonado, reactivo de Kovac's, Caldo Tetrationato, solución de iodo, Agar Salmonella-Shigella, Agar TSI, Agar LIA.

\subsection{Métodos}

1.- Recuento total de bacterias aerobias mesófilos viables.

2.-Numeración de hongos y levaduras.

3.- NMP de coliformes totales.

4.-Identificación de E.coli.

5.-Numeración de Staphylococcus aureus.

6.-Identificación de Salmonella.

Los análisis se realizaron según los métodos recomendados porla FAO.

\section{RESULTADOS}

\subsection{Condiciones de venta de los helados en la ciudad de} Tacna.

En la ciudad de Tacna se venden helados industrializados, semi-artesanales y artesanales.

Los helados industrializados son los más destacados y salen a la venta en envases plastificados adecuados para cada variedad, y en nuestra ciudad se les observa conservados durante la venta en congeladoras de mediano tamaño a temperaturas de -18 a $-20^{\circ} \mathrm{C}$ en supermercados, en diversas pequeñas tiendas de abarrotes, en cafés, y también son vendidos en carretillascongeladoras-ambulatorias con una apreciable y constante aceptación del público. Sin duda esto se debe a la calidad de estos productos que es cuidadosamente controlada. Durante la venta, por el buen sellado de los envases no existe la posibilidad de contacto directo con el vendedor, lo cual hace que el consumidor posea confianza con respecto a la higiene de estos helados. Sin embargo estos helados se venden también a granel, en pequeñas porciones generalmente en conos de galleta (wafer), o en vasitos de 
vidrio, donde si existe contacto con el vendedor,es en este caso en que la recontaminación debe ser evitada aplicando las buenas prácticas de higiene y una correcta manipulación de estos productos, pues sus ingredientes son muy ricos en sustancias nutritivas y los microorganismos podrían reproducirse con facilidad, (en especial los estafilococos y coliformes).

Los helados semi-artesanales que se venden son helados de consistencia-soft (suave), no endurecidos a temperaturas de congelación, son bastante agradables al paladar, en los supermercados es donde se consideran y guardan mejor los cuidados durante la venta, los vendedores en forma rápida se desinfectan las manos antes de servir a cada cliente y utilizan ropa adecuada y servilletas para no hacer contacto con los conos de galleta. Este tipo de helados se ha difundido cada vez más, en las principales avenidas de la ciudad, existen otros centros bastante concurridos, donde la atención al público es también cuidadosa. Además, de invierno 2013 a verano 2014, han abierto dos heladerías en la Plaza de Armas y av. San Martín, y dos en la av. 2 de mayo, son pequeñas heladerías donde utilizan también maquinaria para la elaboración de helados soft, en las cuales hay que tener especial cuidado en la desinfección de los dosificadores y boquillas de las máquinas.

En la venta de helados endurecidos por congelación destacan varias heladerías. Allí se venden los helados como postre, o en forma de bebida (milkshake), se practican con interés las buenas prácticas de higiene, utilizando ropa adecuada, servilletas y, en algunos casos envases de teknopor y cucharitas descartables. Estos lugares son bastante concurridos por turistas chilenos provenientes de la ciudad de Arica.

En algunos mercadillos de la ciudad venden helados semi artesanales y artesanales. En avenidas principales como la av. Leguía se observa la venta de helados en carretillas de diversas procedencias donde les añaden crema de chocolate, caramelos y otros aditivos. Es necesario indicar que en estos casos es difícil el control de las temperaturas de conservación de los helados, tiempo de vida útil y fechas de vencimiento de estos productos. Los vendedores no usan ropa adecuada, y en los meses de verano la temperatura del medio ambiente alcanza valores mayores a $30^{\circ} \mathrm{C}$, lo cual puede favorecer al desarrollo de los microorganismos.

\subsection{Resultados de los análisis microbiológicos de muestras de helados. \\ Ver Tabla $\mathrm{N}^{\circ} 01$.}

\section{Figura $\mathbf{N}^{\circ} 01$. Colonias de Staphylococcus aureus en medio de cultivo Agar Baird Parker.}

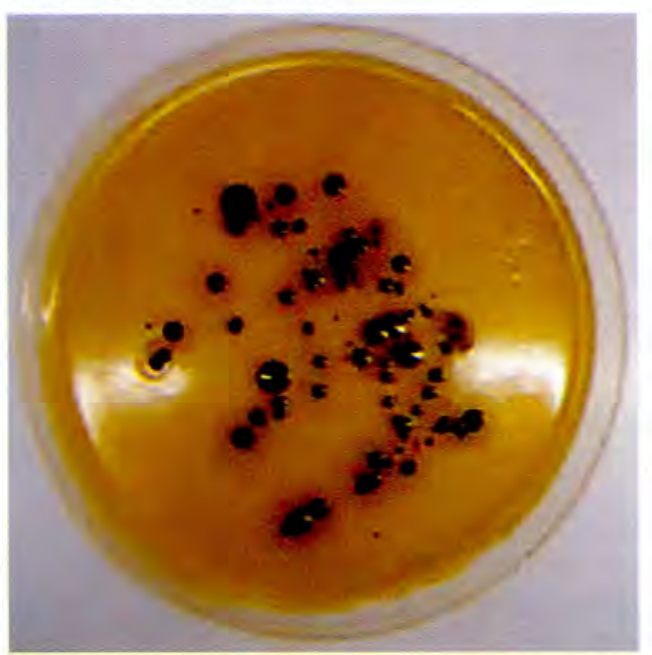

Tabla N01. Resultados de análisis microbiológicos de muestras de helados

\begin{tabular}{|c|c|c|c|c|c|c|c|c|c|}
\hline $\begin{array}{l}\text { Muestra } \\
\text { Análisis }\end{array}$ & 1 & 2 & 3 & 4 & 5 & 6 & 7 & 8 & 9 \\
\hline RTBAMV & $1 \times 10^{3} \mathrm{ufc} / \mathrm{g}$ & $2 \times 10^{3} \mathrm{ufc} / \mathrm{g}$ & $14 \times 10^{3} \mathrm{ufc} / \mathrm{g}$ & $11 \times 10^{3} \mathrm{ufc} / \mathrm{g}$ & $13 \times 10^{4} \mathrm{ufc} / \mathrm{g}$ & $31 \times 10^{5} \mathrm{ufc} / \mathrm{g}$ & $73 \times 10^{4} \mathrm{ufc} / \mathrm{g}$ & $6 \times 10^{7} \mathrm{ufc} / \mathrm{g}$ & $1 \times 10^{4} \mathrm{ufc} / \mathrm{g}$ \\
\hline $\begin{array}{l}\text { Numeración de } \\
\text { Hongos y }\end{array}$ & $\begin{array}{l}\text { Hongos: } \\
<10 \mathrm{ufc} / \mathrm{g}\end{array}$ & $\begin{array}{l}\text { Hongos: } \\
<10 \mathrm{ufc} / \mathrm{g}\end{array}$ & $\begin{array}{l}\text { Hongos: } \\
<10 \text { ufc/g }\end{array}$ & $\begin{array}{l}\text { Hongos: } \\
<10 \text { ufc/g }\end{array}$ & $\begin{array}{l}\text { Hongos: } \\
<10 \mathrm{ufc} / \mathrm{g}\end{array}$ & $\begin{array}{l}\text { Hongos: } \\
<10 \text { ufc/g }\end{array}$ & $\begin{array}{l}\text { Hongos: } \\
<10 \text { ufc/g }\end{array}$ & $\begin{array}{l}\text { Hongos: } \\
\text { <10ufc/g }\end{array}$ & $\begin{array}{l}\text { Hongos: } \\
<10 \text { ufc/g }\end{array}$ \\
\hline levaduras. & $\begin{array}{l}\text { Levaduras: } \\
\text { <10ufc/g }\end{array}$ & $\begin{array}{l}\text { Levaduras: } \\
2200 \mathrm{ufc} / \mathrm{g}\end{array}$ & $\begin{array}{l}\text { Levaduras: } \\
\text { 3500ufc/g }\end{array}$ & $\begin{array}{l}\text { Levaduras: } \\
700 \text { ufc } / g\end{array}$ & $\begin{array}{l}\text { Levaduras: } \\
3 \times 10^{6} \text { ufc/g }\end{array}$ & $\begin{array}{l}\text { Levaduras: } \\
81 \times 10^{6} \text { ufc } / \mathrm{g}\end{array}$ & $\begin{array}{l}\text { Levaduras: } \\
38 \times 10^{4} \mathrm{ufc} / \mathrm{g}\end{array}$ & $\begin{array}{l}\text { Levaduras: } \\
9 \times 10^{7} \mathrm{ufc} / \mathrm{g}\end{array}$ & $\begin{array}{l}\text { Levaduras: } \\
26 \times 10^{4} \text { ufc } / g\end{array}$ \\
\hline $\begin{array}{l}\text { Numeración de } \\
\text { Stapbylococcus } \\
\text { aureus. }\end{array}$ & $<100 \mathrm{ufc} / \mathrm{g}$ & $1100 \mathrm{ufc} / \mathrm{g}$ & $2900 \mathrm{ufc} / \mathrm{g}$ & $<100 \mathrm{ufc} / \mathrm{g}$ & $6 \times 10^{3} \mathrm{ufc} / \mathrm{g}$ & $24 \times 10^{3}$ ufc $/ g$ & $<100 \mathrm{ufc} / \mathrm{g}$ & $12 \times 10^{5} \mathrm{ufc} / \mathrm{g}$ & $<100 \mathrm{ufc} / \mathrm{g}$ \\
\hline $\begin{array}{l}\text { NMP de } \\
\text { Coliformes } \\
\text { totales. }\end{array}$ & $<3 / g$ & $<3 / g$ & $>1100 / \mathrm{g}$ & $<3 / g$ & $15 / g$ & $200 / \mathrm{g}$ & $11 / \mathrm{g}$ & $>1100 / \mathrm{g}$ & $9 / \mathrm{g}$ \\
\hline $\begin{array}{l}\text { Detección de } \\
\text { E.coli. }\end{array}$ & Ausente/g & Ausente/g & Ausente/g & Ausente/g & Ausente/g & Ausente/g & Ausente/g & Ausente/g & Ausente/g \\
\hline $\begin{array}{l}\text { Detección de } \\
\text { Salmonella }\end{array}$ & Ausente $/ 10 \mathrm{~g}$ & Ausente $/ 10 \mathrm{~g}$ & Ausente $/ 10 \mathrm{~g}$ & Ausente $/ 10 \mathrm{~g}$ & Ausente $/ 10 \mathrm{~g}$ & Ausente $/ 10 \mathrm{~g}$ & Ausente $/ 10 \mathrm{~g}$ & Presente $/ 10 \mathrm{~g}$ & Ausente $/ 10 \mathrm{~g}$ \\
\hline
\end{tabular}

\section{Muestras:}

1.- Helado industrializado en vasito de plástico. Sabor lúcuma -vainilla. $(60 \mathrm{~g})$

2.- Helado semi-artesanal en vasito de teknopor .Sabor chocolate-vainilla. (100g)

3.- Helado semi-artesanal en vasito de teknopor .Sabor fresavainilla. $(150 \mathrm{~g})$.

4.- Helado industrializado de envase de 10 litros, venta a granel.

Sabor: vainilla con chocochips. $(50 \mathrm{~g})$
5.- Helado artesanal, venta a granel. Sabor: fresa-lúcuma. (40g) 6.- Helado semi-artesanal. Venta en carretilla. Sabor: Vainilla, fresa, chocolate. $(50 \mathrm{~g})$

7.- Helado artesanal. Venta en carretilla. Sabor: Chicha morada. $(50 \mathrm{~g})$

8.- Helado artesanal. Venta en carretilla. Sabor: vainillachocolate. $(50 \mathrm{~g})$

9.- Helado semi-artesanal. Sabor: vainilla-fresa. (100g) 


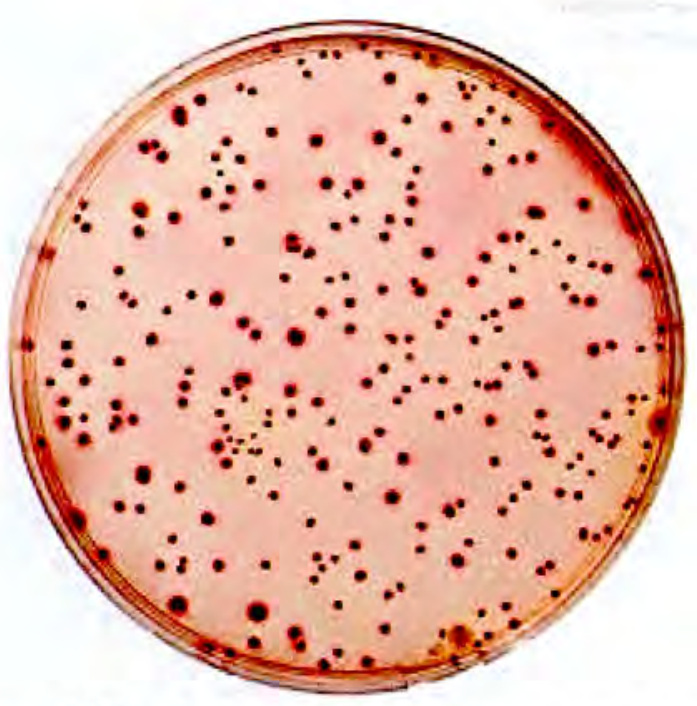

Figura $\mathrm{N}^{\circ} 02$. Colonias de coliformes en medio de cultivo VRBA.

\section{IV.DISCUSIÓN}

De acuerdo a los resultados de los análisis microbiológicos, destaca la muestra 1 , la cual debido al envase, temperatura y tiempo de conservación, y al proceso tecnológico de elaboración utilizado (nivel industrial), mantiene una calidad microbiológica casi estéril. Observa un recuento de bacterias aerobias mesófilas viables (RTBAMV) de $1000 \mathrm{ufc} / \mathrm{g}$ y la ausencia de levaduras, lo cual indica una correcta aplicación de las BPM.

$\mathrm{Al}$ mismo tiempo se observa un gran contraste con la muestra 8 , la cual alcanza valores inaceptables de los principales indicadores microbiológicos, sin duda, este producto atenta contra la salud pública al presentar bacterias lactosa negativas patógenas (Salmonella), presencia elevadísima de levaduras, estafilococos y de bacterias según el RTBAMV (60 millones ufc/g). Esto demuestra la facilidad con que los microorganismos pueden reproducirse en los helados cuando no se toman en cuenta el control de temperatura de conservación y posiblemente la incorrecta pasteurización de la materia prima y demás ingredientes; la manipulación del helado con seguridad fue inadecuada.

La muestra 6 tampoco demuestra una buena calidad microbiológica, la presencia de bacterias, levaduras, estafilococos y coliformes indican una mala manipulación del producto final a pesar de ser un helado semi-industrial, la venta en carretilla a granel, mediante vasitos de barquillo, $\sin$ el debido control de la temperatura de conservación, no garantizan un buen producto.

La muestra 4 es de la misma procedencia que la muestra 1, sólo que la venta se realizó a granel en pequeñas porciones desde envases de 10 litros. Posee una carga microbiana 10 veces mayor que de la muestra 1 . Esto demuestra la importancia que tiene el mantener durante la venta las buenas prácticas de higiene, el mantener el producto lejos del aire contaminante de los lugares públicos, el mantener cerradas las congeladoras mientras no se vende, el usar mandiles limpios, utensilios desinfectados, y el uso de mascarillas para evitar la proliferación de estafilococos. Sin embargo esta muestra cumple con las normas legales microbiológicas para su consumo.

La muestra 5 no cumple con los requisitos microbiológicos sanitarios.

Se observa lo difícil que es controlar el desarrollo de las levaduras en los helados, este crecimiento de levaduras se observa en todas las muestras a excepción de la muestra 1. La presencia de esporas las hace más resistentes, además de la presencia de azúcares, y aire en los helados. Sin embargo un control rápido de la temperatura podría disminuir estos valores.

La muestras 2 y 3 poseen un RTBAMV, aceptable, sin embargo la numeración de estafilococos podría disminuir cuidando la asepsia del aire y medio ambiente del área de venta, además haciendo que los vendedores usen mascarillas.

Las muestras 7 y 9 presentan un NMP de coliformes totales y un RTBAMV aceptables. No hay presencia de estafilococos.

En ninguna muestra se encontró presencia de $E$. coli, lo cual demuestra la no contaminación fecal.

No se encontró presencia de hongos. muestra 8.

La presencia de Salmonella sólo se observa en la

\section{CONCLUSIONES}

1. El grado de contaminación del producto final de los helados depende además de la composición de los ingredientes, de la aplicación correcta de las BPM para helados, de la conservación de la temperatura de almacenamiento y del uso de las buenas prácticas de higiene durante el proceso de venta. Esto se cumple principalmente para los helados que se elaboran artesanal y semiartesanalmente.

2. En la ciudad de Tacna, no son muchas las heladerías en establecimientos céntricos, pero en éstas sí se practican las BPM. La venta de helados artesanales y semiartesanales se realiza también en carretillas que no siempre tienen las correctas condiciones de limpieza. Pero todos estos centros de venta son bastante concurridos por niños, personas mayores y de la tercera edad de nuestra localidad, $y$ muchos turistas chilenos provenientes de la ciudad de Arica.

3. Los helados en su composición, poseen leche, grasa de leche, azúcares, pulpas de frutas que son rápidamente contaminables por microorganismos si es que no se controla correctamente el proceso de pasteurización, envasado, temperatura de conservación y las buenas prácticas de higiene durante el proceso de venta.

4. Los helados, además, son postres que poseen excelentes características organolépticas, siendo la atracción, sobre todo en los meses de verano $\left(28-31^{\circ} \mathrm{C}\right)$ de toda la población, la cual debe ser protegida a través de controles sanitarios constantes.

5. El RTBAMV frente a incorrectas prácticas de higiene puede alcanzar valores elevadísimos de 60 y más millones de ufc/g en los helados.

6. El NMP de coliformes totales (los cuales provienen, del suelo, manos, vestimenta de trabajadores, utensilios, mesas de trabajo, maquinarias no desinfectadas, 
dosificadores, etc.) en algunas muestras alcanzó valores $>1100 / \mathrm{g}$, lo cual indica que debe de existir una mayor preocupación por la higiene en la elaboración y venta de helados.

7. En las muestras observadas no se detectó contaminación fecal a través de E. coli.

8. Algunas muestras presentan elevada numeración de Stapbylococcus aureus (del orden de 1100 hasta 1 millón de ufc/g), bacterias termorresistentes causantes de intoxicaciones.

9. Se ha observado elevada numeración de levaduras en casi todas las muestras (desde miles hasta 90 millones de ufc/g), a excepción de la muestra 1 . Esto indica la gran dificultad existente para poder evitar el desarrollo de levaduras en los helados artesanales y semi-artesanales.

\section{REFERENCIAS BIBLIOGRÁFICAS}

Altaert Vandevenne, Corrie. Métodos de análisis microbiológicos de alimentos. Madrid. 248 pág.

Biletova, V.; Kornelaeva, R. P. Microbiología Sanitaria. Edit. Ind. Alimentarias-Moscú. 352 pag.

Cheesman J. E. Bacterial content of ice cream. The Lancet,
Volume 209

Codex alimentarius ONU para la agricultura y la Alimentación.

Díaz C. y Rosales. Y. Evaluación de la calidad microbiológica de helados caseros en Mérida Venezuela. Laboratorio de Microbiología de alimentos. Facultad de farmacia y bioanálisis. Universidad de los andes. Mérida Venezuela.

Doyle M. Microbiología de los alimentos: fundamentos y fronteras. Edt. Acribia S.A. Zaragoza, España.

Forsythe Stephen J. Alimentos seguros: microbiología. Zaragoza. 400 pág.

Ilenko-Petrovskaya, T.P.; Buxtareva, E. F. Elaboración de grasas alimenticias, y productos lácteos. Moscú. 304 pag.

Mossel D.A.A. Microbiología de los Alimentos. Ed. Acribia Zaragoza. España. 375 pag.

Taboada R. Ly otros. Helado total. Publitec Editora. Buenos Aires. Argentina.

Timm f. Fabricación de Helados. Ed.Acribia S.A. Zaragoza, España.

Yousef, Ahmed E. Microbiología de los alimentos manual de laboratorio. Ed. Acribia Zaragoza. España. 303 pag.

\section{Correspondencia:}

Amelia Castro Gamero: ameliaecg@hotmail.com
Fecha de Recepción: 12/05/2014

Fecha de Aceptación: 02/07/2014 